\title{
Hacia una eclesiología responsable. Sobre la iglesia de los mártires en El Salvador, según Mons. O. A. Romero e I. Ellacuría
}

\begin{abstract}
Juan Vicente Chopin ${ }^{1}$
El presente artículo afronta el tema del martirio cristiano desde la perspectiva de la responsabilidad. En primer lugar se establece la relación entre el ministerio episcopal de Mons. Oscar Arnulfo Romero y la teología de Ignacio Ellacuría, como ejemplos concretos de la actualidad del martirio, y para establecer la relación entre praxis eclesial y eclesiología. En segundo lugar, se presenta el martirio desde la categoría de sacramento, evidenciando que esa dimensión tiene una fuerte base antropológica, filosófica y litúrgico-sacramental, los ejemplos presentados son el bautismo y la eucaristía. La conclusión presenta a la iglesia desde una sacramentalidad responsable, es decir, los mártires es lo más creíble de la realidad eclesial, porque en ellos se da el mayor grado de cercanía entre Dios y los hombres.
\end{abstract}

This article presents the topic of Christian martyrdom from the perspective of the concept of commitment. First, the article establishes the relation between the Episcopal ministry of Archbishop Oscar Arnulfo Romero and the theology of Ignacio Ellacuría in order to provide particular examples of the actualities of martyrdom and to establish the relation between ecclesial praxis and ecclesiology. Second, martyrdom is presented from the category of Sacrament, to demonstrate that such dimension has a strong anthropological, philosophical, and liturgical-sacramental basis; the examples given are the Baptism and the Eucharist. The conclusion presents the church as a deep sacramental commitment. In other words, the martyrs are the most credible ones of ecclesial reality, because in these the highest bond between God and mankind takes place.

\section{Introducción}

La teología latinoamericana ha encontrado en los mártires una rica fuente de inspiración para su reflexión teológica. Pero esa teología no sólo "tiene mártires", sino que es martirial. Testimonios como el del arzobispo de San Salvador, Oscar Arnulfo Romero y el del teólogo Ignacio Ellacuría, siguen inspirando muchas de las actuales intuiciones teológicas.

En este sentido se puede decir que el ministerio de Oscar Arnulfo Romero tiene continuidad en la reflexión teológica actual. En realidad, en ese soporte

1. Doctor en Teología. Director de la Escuela de Teología, de la Universidad Don Bosco. 
martirial reside la fuerza de la teología latinoamerica hoy.

En este artículo se afrontan dos cuestiones: por una parte, intentamos acoger la herencia teológica y testimonial de I. Ellacuría, en aquello que respecta su eclesiología, si bien no tratada en modo exhaustivo. Por otra parte, a partir del testimonio de 0 . A. Romero y de I. Ellacuría, planteamos la hipótesis según la cual una práctica eclesial responsable y creíble en Latinoamérica no sólo ha sido posible, sino que es necesaria.

\subsection{Una eclesiología con responsabilidad histórica: el sentido de la iglesia en I. Ellacuría}

El intento teológico de Ellacuría fue el de realizar el reino de Dios en la historia, concibiendo a la iglesia al servicio de esa realización. Los elementos esenciales de su principal legado teológico son: primero, su lectura y aplicación del pensamiento zubiriano a la realidad latinoamericana, evidente en su «realismo histórico" 2 ; segundo, el modo como relaciona reino de Dios e iglesia; en fin, la relación de su vida y de su obra con el testimonio de O. A. Romero. Estos son algunos de los elementos que presentamos en la primera parte de este artículo.

Para I. Ellacuría el anuncio del evangelio, si no parte de la esencial historicidad de la iglesia, se torna algo superfluo y presuntuoso ${ }^{3}$. Por tal motivo, uno de sus principales esfuerzos fue precisar el sentido de la historicidad de la salvación o como él mismo prefería decir: «qué tiene que ver la historia de la salvación con la salvación de la historia» ${ }^{4}$.

En su teología política ${ }^{5}$ Ellacuría sostenía que era necesario tomarse en serio el fenómeno de la secularización: había que verla no como un fenómeno menor del cual la teología no tuviera que preocuparse tanto. En esta perspectiva I. Ellacuría lanza una tesis que, cuando la dijo (1972) y en el contexto en que la dijo (El Salvador), podía sonar como fuera de puesto, es decir, que si la secularización es un hecho, entonces, sólo una fe y una teología secularizadas tienen sentido, o pueden tenerlo al menos, para un mundo crecientemente secularizado .

Anteriormente, ya el teólogo protestante Bonhoeffer -también mártir- hizo un llamado a tomarse en serio la realidad mundana. Ambos autores, si bien en términos diversos, hablan de una responsabilidad de frente al mundo. Para

2. Cfr. I. ELLACURÍA, Filosofía de la realidad histórica, UCA Editores, San Salvador 1990.

3. Cfr. I. ELLACURÍA, «Anuncio del reino y credibilidad de la iglesia», en ID., ET, vol. 1, UCA Editores, San Salvador 2000, 659-698.

4. Cfr., I. ELLACURÍA, «Historicidad de la salvación», en ID., ET, vol. 1, 519-628.

5. I. ELLACURÍA, Teología política, UCA Editores, San Salvador 1972.

6. I. ELLACURÍA, «Historicidad de la salvación», 523. 
Bonhoeffer «en Cristo se nos ofrece la posibilidad de llegar a participar simultáneamente en la realidad de Dios y la realidad del mundo; la una no se da sin la otra» ${ }^{7}$. La constatación de estos dos mártires es que «no hay dos realidades, sino solamente una realidad, y esta es la realidad de Dios en la realidad del mundo, que se ha revelado en Cristo ${ }^{8}$. No tiene sentido, entonces, buscar un cristianismo real fuera de la realidad del mundo, o una humanidad real fuera de la realidad de Jesucristo 9 . Esta apertura al mundo, tiene consecuencia en la visión que nosotros tenemos del mundo, una de ellas es que la iglesia no busca disputarle al mundo un fragmento de su territorio, sino que busca testimoniar al mundo que sigue siendo el mundo, es decir, el mundo querido y reconciliado por Dios $^{10}$.

En Bonhoeffer, la religiosidad humana ${ }^{11}$ remite al hombre, en su necesidad, al poder de Dios en el mundo: así Dios es el deus ex machina. Pero la Sagrada Escritura lo remite a la debilidad y al sufrimiento de Dios; sólo el Dios sufriente puede ayudarnos. En este sentido, la evolución hacia la edad adulta del mundo, de la que habla el autor, al dar fin a toda falsa imagen de Dios, orienta la mirada del hombre hacia el Dios de la Biblia, el cual adquiere poder y sitio en el mundo gracias a su impotencia. Aquí es donde deberá entrar en juego la “interpretación mundana”12.

Según esto no es difícil entender cómo los cristianos están con Dios en su pasión, y están llamados a sufrir con Dios en el sufrimiento que el mundo sin Dios inflige a Dios ${ }^{13}$. El mundo adulto es más sin Dios, y quizá por ello está más cerca de Dios que el mundo "menor de edad". Así, dice el teólogo, «hemos de vivir en el mundo etsi deus non daretur ${ }^{14}$ ("como si Dios no fuera algo dado" o "como si Dios no existiera").

Actualmente parece que las tesis de I. Ellacuría y de D. Bonhoeffer se refuerzan si se piensa que la secularización puede ser vista como un «denominador común", que no es sólo superación del monopolio religioso medieval, sino un tiempo de fundación nueva ${ }^{15}$.

En todo caso, lo que interesa a I. Ellacuría, no es tanto el debate teórico que se ha generado sobre la secularización, sino más bien algo más simple, esto es,

7. D. BONHOEFFER, Etica, Trotta, Madrid 2000, 47.

8. D. BONHOEFFER, Etica, 50.

9. Cfr. D. BONHOEFFER, Etica, 52.

10. Cfr. D. BONHOEFFER, Etica, 54.

11. Aquí por "religiosidad" hay que enteder no la fe o una profunda espiritualidad y comunitaria, sino en el sentido en que lo entendía el teólogo protestante Barth, es decir, como mero sentimiento o fenómeno religioso circunscrito a lo meramente humano.

12. D. BONHOEFFER, Resistencia y sumisión. Cartas y apuntes desde el cautiverio, Sígueme, Salamanca 2001, 253.

13. Cfr. D. BONHOEFFER, Resistencia y sumisión, 253.

14. D. BONHOEFFER, Resistencia y sumisión, 252.

15. Cfr. C. DOTOLO, Un cristianesimo possibile, Queriniana, Brescia 2007, 46. 
que la iglesia se tome en serio la situación histórica concreta del pueblo al cual sirve. Este es, pues, el primer elemento de herencia que I. Ellacuría propone: la superación del prejuicio de la historicidad de la iglesia, que da prioridad a lo idéntico, respecto de lo dialéctico. Se reafirma así la unidad entre historia de la salvación e historia de la humanidad, aunque esto suponga el tener que continuar confrontándose con el idealismo y con el marxismo ${ }^{16}$.

En cuanto respecta el ejercicio responsable de la eclesiología, ya sería suficiente con apelar a la vida y al testimonio martirial de I. Ellacuría ${ }^{17}$, pero esto no haría justicia a su habitual modo de justificar razonablemente sus posiciones teológicas, por ello es necesario saber cuál es el elemento que lo lleva a concebir la eclesiología como participación directa en el proceso de realización del reino de Dios. La respuesta podría remontarse hasta lo que I. Ellacuría llama «voluntad de fundamentalidad y voluntad de verdad» ${ }^{18}$, pero eso nos llevaría hasta las altas especulaciones filosófico-teologales entre Zubiri e I. Ellacuría, preferimos mejor ir directamente a lo que él llama «hacerse cargo de la realidad ${ }^{19}$.

Según I. Ellacuría, «la estructura formal de la inteligencia [...], no es la de ser comprensión del ser o captación del sentido, sino la de aprehender la realidad y de enfrentarse a ella ${ }^{20}$. Esta propuesta hermenéutica llevó a I. Ellacuría a plantear la relación del hombre con la realidad en términos de transformación y no de mera contemplación; al decir esto, no excluye la vía marxista, aunque su teología se inspire principalmente en Zubiri, proponiendo tres pasos: primero, tomar conciencia que nuestro estar en la realidad no es un estar "cósico», es decir, como uno más entre los demás objetos, sino un estar en respectividad, es el hacerse cargo de la realidad; esa toma de conciencia debería llevar a la decisión ética de cargar con esa realidad, esto es, la de sentir una responsabilidad por dar respuesta a lo que las cosas exigen; esto, en un proceso normal, debe desembocar en acciones concretas, en encargarse de la realidad.

Ahora bien, ¿hasta qué punto se puede ser responsable en el plano de la fe cristiana y en el ejercicio de la teología? Normalmente, en la vida cristiana, el nivel más alto es llamado martirio y hasta ese nivel llevó I. Ellacuría su teología.

16 Cfr. I. ELLACURÍA, «Historicidad de la salvación», 528-533.

17 Los particulares del asesinato-martirio de I. Ellacuría en Revista de Estudios Centroamericanos 34 (1989), $1125-1171$

18 I. ELLACURÍA, «Voluntad de fundamentalidad y voluntad de verdad: conocimiento-fe y su configuración histórica», en ID., ET, vol. 1, 107-137. Las expresiones voluntad de fundamentalidad y voluntad de verdad, expresan las intuiciones de aquella parte del pensamiento zubiriano que puede ser visto como su teología fundamental, cfr. X. Zubiri, El hombre y Dios, Alianza, Madrid 1984, 20037; D. GRACIA, "Xavier Zubiri», en R. LATOURELLE - R. FISICHELA, Dizionario di teologia fondamentale, Cittadella, Assisi 1990, 1457-1462.

19 Cfr. I. ELLACURÍA, «Hacia una fundamentación», en ID., ET, vol. 1, 207-209.

20 I. ELLACURÍA, «Hacia una fundamentación», 207. 
En resumen, el ejercicio de la eclesiología en I. Ellacuría consiste en que la iglesia se tome con responsabilidad los desafíos que presenta la realidad histórica, haciéndose cargo, cargando y encargándose de ella; debe hacer que la salvación, en la perspectiva del reino predicado por Jesús, vaya tomando cuerpo en la historia.

Un ulterior elemento que define la misión de la Iglesia en la historia es su condición de signo. Después de que I. Ellacuría ha afirmado la mediación histórica como algo esencial a la revelación de Dios, luego se dispone a especificar aquellos elementos que hacen que esa revelación tome carne en la historia. Intenta, pues, identificar áreas de la realidad en las cuales se puedan encontrar los anhelos fundamentales del pueblo de Dios y los anhelos del pueblo de los hombres. Son tres las dimensiones que reúnen características bíblicas y características seculares: «liberación» como proceso de libertad, «justicia» y «amor». De este modo la iglesia puede encontrar su justa colocación, entre la revelación de Dios y los afanes del mundo, ejercitar, en suma, su sacramentalidad en modo creíble $^{21}$.

Dios sólo es accesible desde la mediación del signo. La iglesia, inspirada en Jesucristo, se inscribe en esa perspectiva. I. Ellacuría, sin romper la unidad de la historia, cree que el signo debe ser histórico para que pueda superar los límites de la pura naturaleza y al ser visto desde la historia de la salvación, supera la arbitrariedad que impone la inmanencia a la que está sujeto el hombre. La clave de lectura está en la historia del viviente Jesús, con la cual se evita caer en un inmanentismo historicista. Cuando se dice que la historia es lugar esencial para la revelación de Dios por tal entiende el campo donde se manifiesta la libertad personal y colectiva, y donde se hace presente el Dios vivo, libre y personal. Si esto es verdad, entonces quiere decir que la credibilidad de la iglesia, aunque apunte a su pública manifestación, en realidad se funda en algo que le es intrínseco, pues, en sentido estricto, la iglesia tiene su quicio en Jesucristo y es a él al que debe manifestar. Este estar centrada en Jesucristo le evita a la iglesia dos visiones reductivas de la salvación: la reducción intimista-subjetiva y la reducción secularista-politizante. Por ello, la historicidad de la revelación en mediación sacramental debe estar abierta al futuro escatológico ${ }^{22}$.

\subsection{A. Romero e I. Ellacuría, la interacción entre praxis eclesial y eclesiología}

La teología de I. Ellacuría ha recibido influjos de Zubiri en el plano filosófico y de 0. A. Romero en el plano pastoral. Aquí consideramos su relación con éste último ${ }^{23}$.

21 I. ELLACURÍA, Conversión de la iglesia al reino de Dios, Sal Terrae, Santander 1984, 219-223.

22 Cfr. I. ELLACURÍA, «Utopía y profetismo desde América Latina», ID., ET, vol. 2, UCA Editores, San Salvador $2000,233-293$.

23 Téngase presente: I. ELLACURÍA, «El verdadero pueblo de Dios, según monseñor Romero», en ID., ET, vol. 2, 357-396. 
A ocho meses del asesinato de O. A. Romero, I. Ellacuría escribió un artículo que ayuda a entender esa mutua relación entre los dos mártires ${ }^{24}$. Poco importa, dice el teólogo, quién lo mató: «fue el mal [...], pero un mal, un pecado y un anti-Cristo históricos, los cuales se han encarnado en estructuras injustas $\gg 25$. ¿En qué radica, dice I. Ellacuría, la eficacia de su ministerio, ejercido siempre como cristiano, como pastor, como profeta y sacerdote?

O. A. Romero es ejemplo de la «fuerza histórica del evangelio». I. Ellacuría subraya el hecho que 0 . A. Romero "consiguió esto no sólo sin salirse de sus funciones episcopales, sino por realizarlas plenamente ${ }^{26}$, no ha hecho la diferencia el hecho mismo de que fuera obispo, sino el modo en que lo fue. Según I. Ellacuría, «la causa última es que se puso a anunciar y realizar el evangelio en toda su plenitud y con plena encarnación»27. Según el rector de la UCA, se forma parte de la iglesia de los mártires sólo por un don del Espíritu Santo que irrumpe en nuestras vidas y nos hace confrontarnos directamente con el pecado histórico, y ante el cual, estamos llamados a tomar una decisión. En O. A. Romero habría sido la muerte del padre Rutilio Grande, como ejemplo de un pueblo masacrado, el que lo llevó a ver la realidad con ojos limpios: «y entonces, se le reveló lo que significaba ser profeta y mártir», así inició la carrera de profeta y mártir, con un encuentro con el sufrimiento de su pueblo, para que la iglesia recuperara su pulso profético rebajado ${ }^{28}$. Pero se dio también la vía inversa, es decir, el pueblo inició a sentir a Dios más cercano a ellos, al Espíritu más operante, a un cristianismo más creíble. Pero, por eso lo mataron y por eso es un mártir, porque se acercó a su pueblo e hizo que el pueblo sintiera cercano a su Dios. Una iglesia vista en perspectiva martirial es siempre cercana al pueblo y el pueblo, incluso en su sentido secular, siente cercana a la iglesia ${ }^{29}$. Además 0 . A. Romero predicó siempre la apertura a la trascendencia ${ }^{30}$, una trascendencia que no se presentaba como abandono de lo humano, sino como su superación y perfeccionamiento. El ejemplo de O. A. Romero hacía creíble el mensaje cristiano. Nunca en El Salvador la iglesia ha sido tan creíble como en ese momento histórico ${ }^{31}$.

Así como I. Ellacuría concibe a la iglesia, como encarnación de la salvación en un proceso histórico concreto, así 0 . A. Romero le sirve de ejemplo para su eclesiología: «por eso puede hablarse de que con él se empezó a realizar, de un modo sorprendentemente eficaz, la salvación del proceso histórico, que se está

24 I. ELLACURÍA, «Monseñor Romero, un enviado de Dios para salvar a su pueblo», en ID., ET, vol. 3, UCA Editores, San Salvador 2002, 93-100.

25 I. ELLACURÍA, ET, vol. 3, 93.

26 I. ELLACURÍA, ET, vol. 3, 94.

27 I. ELLACURÍA, ET, vol. 3, 94-95.

28 I. ELLACURÍA, ET, vol. 3, 96, 113.

29 I. ELLACURÍA, ET, vol. 3, 98.

30 I. ELLACURÍA, ET, vol. 3, 106.

31 I. ELLACURÍA, ET, vol. 3, 104. 
cumpliendo en El Salvador» ${ }^{32}$. Pero, este identificarse con un proceso histórico concreto necesita una aclaración, es decir, el evangelio necesita encarnarse en, pero no identificarse con un determinado proceso histórico.

No es casual que I. Ellacuría haya tomado, de lo que O. A. Romero entiende por pueblo, el elemento que le ha servido para hablar de un pueblo perseguido y en definitiva crucificado. En el concepto de pobreza, según I. Ellacuría, O. A. Romero integra las mayorías empobrecidas a causa de la marginación social, las organizaciones populares reprimidas que piden un gobierno más popular y todos los que, aun sin estar organizados, luchan y apoyan la causa popular. Fue este pueblo el que llevó a 0 . A. Romero hasta el testimonio de la palabra y de la sangre. Y no ha de entenderse este amor a los pobres como odio de clase contra los ricos.

Partiendo de la tesis de que ninguna realización histórica alcanza el ideal que el reino de Dios exige para los hombres y para los pueblos y que el reino de Dios no es paralelo a los proyectos políticos temporales, sino su fermento, I. Ellacuría resalta las principales características que deben configurar la interacción entre reino de Dios y luchas populares ${ }^{33}$. Los elementos resaltados son: la compasión, la misericordia y la fe en los pobres.

Se puede concluir que «la teología misma tiene una esencial forma profética y testimonial ${ }^{34}$, que en una situación de persecución la verdadera iglesia y la teología participan en modo solidario con las víctimas de la persecución y, en la perspectiva de los derechos humanos, de la represión contra los movimientos que piden justicia. No es extraño actualmente hablar de «mártires de la justicia» ${ }^{35}$. Aquí tenemos una de las peculiaridades de la iglesia martirial del siglo XX, no se persigue a la iglesia porque sus dogmas se vean amenazados o porque el estado quiera expropiarle sus bienes inmuebles o porque, en definitiva se ataque la fe cristiana. Aquí la única cuestión que hace enojar al perseguidor es que la iglesia se ha posicionado como escudo de defensa entre la violencia de los gobiernos corruptos y el pueblo oprimido, aquí la iglesia es perseguida, porque superando su condición de masa y a partir de su especificidad cristiana y actuando como "conciencia crítica de la sociedad» ${ }^{36}$, defiende hasta las últimas consecuencias los derechos de la persona ${ }^{37}$. Esto quiere decir, que en la visión nueva del martirio, hay que contar ya sea con los motivos políticos como con los motivos teológicos. Políticos porque estos mártires son asesinados no por

32 I. ELLACURÍA, ET, vol. 3, 100.

33 Cfr. I. ELLACURÍA, Conversión de la iglesia, 100.

34 Cfr. PELLITERO Ramiro, «La fuerza del testimonio cristiano», en Scripta teologica 39 (2007), 387.

35 Cfr. G. BOF, Il martire oggi. Per una teologia della giustizia, Paoline, Milano 1999, 275-281.

36 O. A. ROMERO, SP, vol. 4, Arzobispado de San Salvador, San Salvador 2000, 43; O. A. ROMERO, SP, vol. 5 , Arzobispado de San Salvador, San Salvador 2000, 50.

37 También el martirio de $M$. Kolbe es visto en esta nueva perspectiva, cfr. J. SIKORSKI, «Padre Massimiliano Kolbe. Il martire di Auschwitz», en La Civiltà Cattolica 133 (1982, IV), 246. 
su específica profesión de fe cristiana ante un tribunal no-cristiano, sino para frenar la emancipación que la opción por los pobres comporta. Teológicos porque aquí el reino de Dios verdaderamente fermenta toda la masa y no se circunscribe sólo a los límites intraeclesiales ${ }^{38}$.

La cosa más importante es que la persecución configura históricamente al pueblo de Dios, se da esa dinámica fundamental de pasar del «no-pueblo» al ser «pueblo de Dios» (cfr. 1Pe 2,10), pues el pueblo de Dios sólo puede ser el pueblo de uno que murió crucificado y que sólo después de su muerte resucitó.

Con estas resumidas observaciones hemos querido presentar la interacción que se da entre la eclesiología de I. Ellacuría y la praxis pastoral de 0 . A. Romero en condiciones de persecución. Si se quisiera sintetizar lo que I. Ellacuría entendía por tal interacción entonces habría que considerar sus propias palabras: «en pocos casos, como en el de Monseñor Romero, podrá encontrarse un ejemplo tan admirable de cómo juntar los intereses del pueblo con los intereses de Dios, la historia con la transcendencia, el hombre caído con el hombre elevado, el pueblo con el verdadero pueblo de Dios» ${ }^{39}$.

\section{La sacramentalidad responsable}

El martirio es la máxima expresión de la sacramentalidad. Por diversos motivos. Sobre todo porque, si damos por aceptado que Jesucristo es el verdadero y proprio sacramento ${ }^{40}$, y si nosotros hemos conocido el significado de su sacramentalidad sólo a partir de su muerte en cruz, entonces, el mártir, en la medida de sus posibilidades significantes, revela la forma cristiana de la muerte ${ }^{41}$. Pero además, si la iglesia debe ser la santa iglesia también subjetivamente, y si esta santidad debe parecer de verdad como creada por la gracia de Dios, y si eso de hecho se da, entonces puede darse en modo preeminente sólo en el martirio. Siendo la muerte del mártir la muerte cristiana por excelencia, esto significa que el martirio forma parte de la esencia de la iglesia. En fin, en el martirio se cumple aquello que en el signo sacramental del bautismo es ya indicado, morir y ser bautizados en la muerte de Cristo ${ }^{42}$. Ello lleva a considerar que la sacramentalidad de la iglesia no es sólo un aspecto del cuerpo doctrinal de la iglesia, al cual teneos que respetar, sino también algo que se debe poner en práctica con todo el realismo posible. Pero, se requiere, como dice $\mathrm{Ch}$. Duquoc, que la iglesia reconozca su ser provisional, pues la capacidad de cambio y de innovación en las formas eclesiales es el test de la aceptación del "deber morir" para que nazca el reino ${ }^{43}$. La primera

38 Cfr. F. J. BALASUNDARAM, «Martyrdom in the History of Christianity», en Bangalore Theological Forum 25 (1993), 27-36.

39 I. ELLACURÍA, Conversión de la iglesia, 125.

40 Cfr. E. JÜNGEL, El ser sacramental. En perspectiva evangélica, Sígueme, Salamanca 2007, 29.

41 Cfr. K. RAHNER, Sulla teologia della morte. Con una digressione sul martirio, Morcelliana, Brescia 1972, 88.

42 Cfr. K. RAHNER, Sulla teologia della morte, 92-93.

$43 \mathrm{CH}$. DUQUOC, Iglesias provisionales. Ensayo de eclesiología ecuménica, Cristiandad, Madrid 1986, 142. 
dificultad que la iglesia debe vencer, si quiere realizar una sacramentalidad responsable, está en ella misma. Estando colocada en el «intervalo oscuro» entre la opacidad de la historia y la claridad del reino y asumiendo su precariedad, su ambigüedad y sus consecuencias sociales, la iglesia visible entra en el espacio abierto por el modo de aparecer de Dios en Jesús el Cristo, en modo discreto. Esto no niega su institucionalidad, pero le da su justa colocación ${ }^{44}$. Como ha sintetizado De Certeau: «la iglesia está siempre tentada a contradecir aquello que afirma [...], de identificar la verdad con aquello que ella dice de la misma» ${ }^{45}$.

Ahora tratamos de responder a dos cuestiones ¿De cuál responsabilidad estamos hablando? ¿Es posible que la iglesia pueda vivir su sacramentalidad en modo responsable?

\subsection{Responsabilidad, esperanza y martirio}

En el plano ético el ellacuriano «hacerse cargo de la realidad» tiene eco en otros autores, piénsese por ejemplo en el principio responsabilidad de Hans Jonas $^{46}$, cuya filosofía puede ser colocada entre el principio esperanza de E. Bloch y el principio que podemos llamar «anti-esperanza» de Günther Anders ${ }^{47}$ La tesis de Jonas es muy similar a la G. Anders. Los dos autores parten de la conciencia que la promesa de la técnica moderna se ha transformado en una amenaza; a la inmodestia de los objetivos del utopismo escatológico, el principio responsabilidad contrapone la modesta tarea de preservar al hombre, en el residuo ambiguo de su libertad, que ninguna mutación de las circunstancias puede jamás suprimir, la integridad de su mundo y de su estar contra los abusos de su poder: «podemos poner en peligro nuestra vida, pero no la de la humanidad» 48 . Las posibilidades de futuro de la humanidad no son sólo positivas, pueden ser también negativas, de ahí la necesidad de la responsabilidad presente: aquello a que se refiere la responsabilidad en conformidad a su sentido es la vida actual o potencial y, en primer lugar, la vida humana, amenazada por la civilización técnica-científica-industrial; de esas correlaciones temporales se concluye que la responsabilidad no es otra cosa que el complemento moral de la constitución ontológica de nuestra temporalidad.

La posibilidad de una muerte global reclama una conciencia planetaria que nos ayude a comprender que la vida en la superficie de la tierra es una realidad esencialmente precaria. En la actualidad sobrevivir ya no es tan solo expresión de una necesidad, sino que, en adelante, es una auténtica obligación moral, se asiste

44 Cfr. CH. DUQUOC, «Creo en la iglesia». Precariedad institucional y reino de Dios, Sal Terrae, Santander 2001;

ID., «Précarieté institutionelle et Règne de Dieu. Un essai d'ecclésiologie», en Études 393 (2000), 499-511.

45 Cfr. M. DE CERTEAU, Mai senza l'altro. Viaggio nella differenza, Qiqajon, Magnano 2007, 13.

46 H. JONAS, Il principio responsabilità. Un'etica per la civiltà tecnologica, Einaudi, Torino 1990.

47 G. ANDERS, L'uomo è antiquato, 2 vol., Bollati Boringhieri, Torino 2003.

48 H. JONAS, Il principio responsabilità, 17. 
a una auténtica ética de la supervivencia. Se impone, entonces, un humanismo de humildad, donde el ideal de una humanidad que ejerce su soberanía sobre el mundo es una ilusión si no se desciende a un «acuerdo» con la naturaleza; donde la auto glorificación de lo humano resulta fatal para el planeta. Esta moral planetaria nos pide no sólo que liberemos nuestra mente de los espejismos de la cantidad, sino también que emancipemos nuestros cuerpos, que se han habituado a los goces cuantitativos ${ }^{49}$.

En un plano más teológico, D. Bonhoeffer coloca la responsabilidad ante Dios y en favor de Dios, ante los hombres y en favor de los hombres, y siempre se trata de la responsabilidad de la causa de Jesucristo y solo en ella de una responsabilidad de la propia vida. La responsabilidad solo se da, en este caso, en la confesión de Jesucristo.

La estructura de la vida responsable está determinada por un doble elemento: por la vinculación de la vida al hombre y a Dios y por la libertad de la propia vida. Sin esta vinculación y sin esta libertad no hay responsabilidad alguna. La vinculación tiene la figura de la representación y de la acomodación a la realidad, la libertad se muestra en el autoexamen de la vida y de la acción y en el riesgo de la decisión concreta. Ningún hombre puede escapar a la responsabilidad y por tanto a la representación o sustitución. Incluso el hombre solitario vive representando a alguien, y además de manera cualificada. Representación y, por consiguiente, responsabilidad sólo se da en la perfecta oblación de la propia vida a los demás hombres. El responsable no tiene que imponer a la realidad una ley extraña, sino que más bien la conducta del responsable es en sentido auténtico «conforme a la realidad».

Entiéndase que para Bonhoeffer la «realidad» no es en primer término y definitivamente algo neutro, sino el real, es decir, Dios hecho hombre. Todo lo fáctico recibe del que es real, cuyo nombre es Jesucristo, su último fundamento y su definitiva eliminación, su justificación y su definitiva contradicción, su último "sís y su último «no» ${ }^{50}$. Así como la libertad concreta, "efectúa» la $\mathrm{fe}$, la responsabilidad verifica la calidad de la obediencia. Ella encuentra su forma más acabada cuando se pone al servicio y en el puesto de los otros. La «representación» asume una función de línea guía y funciona como una especie de «sacramento» viviente ${ }^{51}$.

Si por responsabilidad se entienden «la totalidad y unidad resumidas de la respuesta a la realidad dada a nosotros en Jesucristo, a diferencia de las respuestas parciales que uno pudiera dar», esto significa, que la total donación de Jesucristo, lleva o nos arrastra a dar una respuesta total, de este modo la

49 Cfr. M. LACROIX, El humanicidio. Ensayo de una moral planetaria, Sal Terrae, Santander 1995.

50 Cfr. D. BONHOEFFER, Etica, 175-234.

51 Cfr. R. MENGUS, Théorie et pratique chez Dietrich Bonhoeffer, Beauchesne, Paris 1978, 463-483. 
responsabilidad significa «que se arriesga la totalidad de la vida, que se trata de vida y muerte ${ }^{52}$. El momento exacto de la responsabilidad se entiende en términos de encuentro, entre la libertad de Dios, cuya revelación nosotros conocemos en Cristo, y la libertad del hombre, cuya precariedad se perfecciona en el testimonio. Rahner diría, desde una visión más existencial, que la relación cristiana al absoluto futuro, que es Dios, no disminuye o suprime, sino radicaliza su responsabilidad por el futuro intramundano, ya que el hombre puede llevar a realización esta disponibilidad a la apertura al futuro absoluto, en manera existentivamente auténtica, solo en una relación, al mismo tiempo crítica y positiva, de responsabilidad y de acción por un futuro intramundano siempre nuevo. Ahora bien, el futuro no está constituido por las posibilidades escondidas en el presente; siendo autofundado en Dios, nos viene al encuentro como la fuerza de su libertad amorosa. El don de Dios se concreta en el Crucificado, en él el futuro prometido entrelaza la libertad y el amor de Dios con la injusticia y la muerte, el sentido último con el sinsentido para mostrar la victoria sobre todo aquello que es negativo. La cruz, más que una figura trágica, es el «seno» del cual nace la nueva creación. El futuro cristiano no puede dejarse aprisionar ni por el realismo de las cosas ni por la historia de los vencedores, siendo en grado de interpelar a fondo la libertad humana, el futuro no puede prescindir del Cristo de Dios ${ }^{53}$.

El tiempo del testimonio es, entonces, un tiempo de esperanza. Pero no se trata de cualquier esperanza, sino de los que murieron esperando («los pueblos crucificados») $)^{54}$, de los cuales la comunidad de creyentes hace memoria, y de los que siguen sufriendo en la actualidad. Es, pues, una esperanza militante, una esperanza-en-acción, la esperanza cristiana porta consigo una dis-conformidad con la realidad ${ }^{55}$. Una esperanza que hunde sus raíces en el evento Jesucristo, y por lo tanto, es vista como una lucha contra la frustración, contra los profetas de la desgracia y del «fin de la historia» ${ }^{56}$, orientándose por una existencia en favor de la vida ${ }^{57}$. Por tanto, es una esperanza que se convierte en el dinamismo que hace salir de la tierra de opresión a la tierra de promisión y no se alimenta de sueños idealistas que sacan de la realidad, sino, más bien, se trata de la aceptación de la promesa liberadora de Dios, actuada hasta dar la vida por otros $^{58}$.

Un último pasaje es saber en qué modo la responsabilidad está relacionada con el martirio y cómo éste, en cuanto muerte cristiana, pueda ser entendido como

52 D. BONHOEFFER, Etica, 202.

53 Cfr. G. COLZANI, La vita eterna, Mondadori, Milano 2001, 28-29.

54 Cfr. el prólogo de J. Sobrino a la obra de X. ALEGRE, Memoria subversiva y esperanza para los pueblos crucificados. Estudios bíblicos desde la perspectiva de la opción por los pobres, Trotta, Madrid 2003, 10.

55 Cfr. J. J. TAMAYO-ACOSTA, Nuevo paradigma teológico, Trotta, Madrid 2003, 20042, 140-141.

56 Típico en este sentido, S. HUNTINGTON, ¿Choque de civilizaciones?, Tecnos, Madrid 2002.

57 Cfr. J. B. LIBÂNIO, «Speranza, utopia, risurrezione», en Mysterium liberationis. Conceptos fundamentales de la teología de la liberación, vol. 2, UCA Editores, San Salvador 1992, 932.

58 Cfr. I. ELLACURÍA, «Utopía y profetismo desde América Latina», 256-258. 
ser-para-la-vida. El martirio, como muerte cristiana, en sentido estricto, no puede ser entendido de otro modo, sino como la paradójica manifestación histórica del Mártir Jesús que dio la vida por la humanidad. La definición Heideggeriana de la existencia como ser-para-la-muerte, obliga a encontrar otro camino, que no se quede en el fatalismo que impone la realidad de la muerte, el saber si es posible ser-para-la-vida y en cuál modo lo sea ${ }^{59}$.

Como advierte Lévinas, Heidegger en la relación tiempo-muerte, lee la muerte a partir de su interés por definir el tiempo. Se da una reducción del tiempo a serpara-la-muerte, a la estructura del Dasein, es decir, todavía a la subjetividad en su origen, la relación con el ser, a partir del cual se comprende al otro. Hay un sólo valor y es el valor de ser, valor puramente formal y en el que se radica el rechazo heideggeriano de los valores. La clave de lectura en Lévinas es el concepto de «responsabilidad» o la visión socio-religiosa de la relación tiempomuerte, la inclusión de «los otros» en el modo de tratar el binomio tiempomuerte y no sólo la visión ontológica del «ser» 0 «ser-existencia individual».

Leyendo a $\mathrm{E}$. Bloch ${ }^{60}$, presenta en sentido contrario a Heidegger la muerte a partir del tiempo ${ }^{61}$. Intenta dejar atrás el análisis de la muerte como momento ontológico, de la muerte como nada y de la temporalidad conectada a la angustia de la nada, para llegar a un pensamiento en el cual el sentido sería todavía conectado al mundo, pero en el que el sentido del mundo es profundamente relacionado a los otros hombres. Es cuanto adviene, según el filósofo, en una filosofía en la que la preocupación social anima el conjunto del saber y de la cultura, y en la cual la terminología ontológica está relacionada con el otro. Lo cual se puede encontrar en un pensamiento social o religioso ${ }^{62}$. La respuesta al tema de la muerte, dice, no puede ser sólo ontológica, sino también ética. Resalta la cuestión que la muerte pone en primer plano la proximidad del próximo, cuestión de que paradójicamente, dice, es mi responsabilidad por su muerte.

Si el mérito de Heidegger ha sido el haber dejado clara la profunda humanidad de la muerte, algo que nos es inmanente y que pertenece a la estructura formal de nuestra vida ${ }^{63}$, en Lévinas se pide que el tema de la muerte pase de la ontología a la dimensión ética, la muerte no se agota en la fatalidad de

59 Heidegger ve el tema de la muerte desde la perspectiva del Dasein. El terminar a que se refiere la muerte no significa un haber-llegado-a-fin del Dasein, sino un estar vuelto hacia el fin de parte de este ente. La muerte es una manera de ser de la que el Dasein se hace cargo tan pronto como él es: «apenas un hombre viene a la vida ya es bastante viejo para morir». Junto a la certeza de la muerte va también la indeterminación de su cuándo. Esto produce un estado de «angustia», que no es mera emoción, y que al superar la posibilidad de convertirse en miedo, se transforma en libertad para la muerte, Cfr. M. HEIDEGGER, Ser y tiempo, Trotta, Madrid 2003, 251286.

60 Cfr E. BLOCH, El principio esperanza, vol. 3, Trotta, Madrid 2007, 204-291.

61 Cfr. E. LÉVINAS, Dio, la morte e il tempo, Jaca Book, Milano 2003, 64-187.

62 Cfr. E. LÉVINAS, Dio, la morte e il tempo, 142.

63 Cfr. G. COLZANI, La vita eterna, 186. 
su individualidad e intransferibilidad, sino que posicionándose «más allá» del concepto metafísico de esencia, nos habla de nuestra responsabilidad ética con los otros.

Pero, con Heidegger y Lévinas estamos siempre en el plano filosófico. En teología la cuestión cambia; en Jüngel, por ejemplo, se habla de «irrelacionalidad» de la muerte, un punto de vista más incisivo, que pone en evidencia la dramaticidad de la muerte. Si Dios no cesa ni siquiera en la muerte de relacionarse con nosotros, es más, si se ha identificado con Jesús, muerto para demostrarse benévolo con todos, entonces, quiere decir que en el corazón de la irrelacionalidad de la muerte ha nacido una nueva relación de Dios con el hombre. Nótese bien: la nueva relación de Dios con el hombre consiste en el hecho que Dios mismo sufre la irrelacionalidad de la muerte que aliena de sí a los hombres. Dios se inserta ahí donde se rompen las relaciones y las relaciones menguan ${ }^{64}$. La única explicación plausible a la muerte como irrelacionalidad es la de ser motivada por el amor, ese es el motivo no sólo del actuar, sino del ser de Dios. Según Tillard, en el destino humano no hay nada de grande y nada que tenga que ver con el amor que no deba pasar por la estrechez del thanatos: no solo el eros, sino su transfiguración evangélica en agape ${ }^{65}$.

En Jüngel, la reflexión sobre la muerte representa el intento de repensar a Dios en la dialéctica de presencia y ausencia, de repensar el hombre al interno de una diferencia cualitativa entre Dios y mundo, entre su cercanía y lejanía, al interno de una dialéctica de revelación. En la muerte misma de Jesús, expresión máxima de la ausencia de Dios, encontramos las huellas, poco visibles pero seguras de su presencia. La ausencia, entonces, de cualquier género -dolor, pecado, muerte, división, fracaso- es cifra, huella, signo, manifestación de la presencia de Dios porque, contemplando el árbol de la cruz, se adquiere un concepto diferenciativo de revelación, se tiene la intuición de la revelación como diferencia, dialéctica entre Dios y el mundo ${ }^{66}$.

La muerte tiene, entonces, una función simbólica y testimonial. K. Kitamori dice que nuestro dolor, y nosotros creemos que también la muerte, «debe testimoniar el dolor de Dios convirtiéndose en el símbolo del dolor de Dios» ${ }^{67}$. Y es que la muerte tiene una fuerte función dialéctica, por una parte limita, pero por otra posibilita. Pero todo el ser humano goza de una función simbólica, pensemos en el ojo, es a la vez la posibilidad indispensable para la vista, pero es su más grande limitación, lo mismo se diga del lenguaje. La muerte, dice, Jankélévitch, no solo nos impide vivir, limita la vida, y luego un día la reduce; sino que al

64 Cfr. E JÜNGEL, Morte, Queriniana, Brescia 1972, 156-157.

65 Cfr. J.-M. TILLARD, La morte: enigma o mistero?, Qiqajon, Magnano 1998, 127.

66 Cfr. TONIOLO Andrea, La theologia crucis nel contesto della modernità. Il rapporto tra croce e modernità nel pensiero di E. Jüngel, H. U. von Balthasar e G. W. F. Hegel, Pontificio Seminario Lombardo/Glossa, Roma/ Milano 1995, 77.

67 K. KITAMORI, Teología del dolor de Dios, Sígueme, Salamanca 1975, 78. 
mismo tiempo comprendemos que sin la muerte el hombre no sería un hombre, que es precisamente la presencia latente de la muerte que favorece las grandes existencias, dando a ellas el fervor, el ardor, el tono específico. Se puede decir, que aquello que no muere no vive ${ }^{68}$.

Hemos considerado necesaria esta premisa sobre la muerte, pues el martirio es una forma de morir, por tanto, las posibilidades que tiene de entrar en el imaginario de los cristianos y de las personas en general, depende mucho de la concepción que de ella se tenga. Esto quiere decir que si «el mundo burgués oculta la muerte ${ }^{69}$, y visto que el martirio es la muerte cristiana, entonces, ¿por qué no habría de ocultar también a éste? Retorna, pues, la necesidad de que los cristianos, en virtud de su bautismo, vivan con responsabilidad el ser testigos de Cristo. En un mundo en donde parece que el capitalismo ha vencido, el pobre y el mártir, se tornan «cuerpos extraños», un pobre o un cristiano que quiera vivir en radicalidad o es aniquilado o asimilado por el sistema, pero se le niega una existencia por libre elección. Ahí donde la memoria de Cristo se hace auténtica y eficaz, ahí el cristiano debe saber que deviene posible beber el cáliz. El martirio no es un proyecto de santificación propia, sino que es un evento en el cual Dios entrega al creyente a los impíos y es un puro don de Dios. Cuando se da el martirio, la solidaridad con los hombres, y en particular con los pecadores, no es desmentida por el mártir, es más, es afirmada, y si el ser «cuerpo extraño» deviene epifanía, inscrita en el testimonio, entonces es ya puesto en movimiento el proceso de reconocimiento del mártir también de parte de sus verdugos ${ }^{70}$.

Si Dios, es un Dios «que lleva» o como prefería decir I. Ellacuría "que carga» con la realidad del pecado. El discípulo, entonces y, por tanto la iglesia, está llamada igualmente a tomarse con responsabilidad el sufrimiento del mundo: «Ser cristiano consiste en llevar. Lo mismo que Cristo, al llevar la cruz, conservó su comunión con el Padre, para el que le sigue cargar la cruz significa la comunión con Cristo» ${ }^{71}$.

\subsection{Ejercicio de la libertad y sacramentalidad del martirio}

Hacerse cargo de los problemas del mundo desde el punto de vista de la fe, es decir, servir a la construcción del reino no es para la iglesia algo opcional, pertenece a su naturaleza sacramental. Ahora bien, su sacramentalidad se refiere, como a su fundamento, a Jesucristo ${ }^{72}$, el cual predijo que el reino de Dios sobre

68 Cfr. VL. JANKÉLÉVITCH, Pensare la morte?, Raffaello Cortina, Milano 1995, 31.

69 J. RATZINGER, Escatología. La muerte y la vida eterna, Herder, Barcelona 2007, 89.

70 Cfr. E. BIANCHI, Cristiani nella società, BUR, Milano 2007, 72-73.

71 Cfr. D. BONHOEFFER, El precio de la gracia. El seguimiento, Sígueme, Salamanca 2004, 27-59.

72 Cuando se dice que la iglesia es sacramento se entiende mysterion, es decir, aquel modo de relación entre la salvación, así como se da en Cristo, y la iglesia que media esa salvación, cfr. S. MAZZOLINI, «La chiesa sacramento del regno", en Gregorianum 86 (2005), 631, 639. 
la tierra se afirmaría sólo por medio de contradicciones y luchas, que podían exigir el sacrificio extremo. Esto quiere decir, que realidades correlacionadas como «cruz», «sufrimiento» y «martirio», no son excepciones en la vida de la iglesia, ni mucho menos cuerpos extraños, todo lo contrario, corresponden a la forma histórica de la iglesia: el martirio posee, innegablemente, una eminente función de signo (sacramento) ${ }^{73}$. Saltarse este principio, afirmando la feliz resurrección de la iglesia, cerrando los ojos al pecado y a la muerte que éste genera en el mundo, sería mutilar la iglesia.

Pues bien, el sentido sacramental del martirio se funda en el evento Jesucristo, el Sacramento primordial ${ }^{74}$. En Jesucristo, la trascendencia de Dios no se entiende como algo más allá de la humanidad, o como contrapuesta a ella, sino como la trascendencia de aquel Dios que se comunica, como la trascendencia que está dentro de la historia en el modo propio del Dios de Jesús ${ }^{75}$. Lo cual significa que así como en la vida de Jesús fue posible la revelación de Dios, así en el mártir, en cuanto expresión del nivel más alto de la experiencia del discipulado, debe ser posible encontrar manifestada la presencia de Dios. Y debe ser posible, además, que de esa disposición fundamental que encontramos en la existencia del mártir se pueda pasar, desde el punto de vista de la fe, a una expresión eclesial del martirio.

El mártir se sitúa en el plano del encuentro de la libertad del hombre con la libertad de Dios, comunicada en Jesucristo. Sólo en este modo se logra superar el fatalismo que impone la muerte natural. El mártir acepta con responsabilidad histórica que su libertad le ha sido donada por Dios, y en cuanto tal, la acoge y al mismo tiempo, desde la fe, da testimonio de ese don. Por tal motivo, el martirio no se refiere sólo al momento puntual del sacrificio violento, esto en el plano natural no especifica nada; el martirio significa algo específico sólo si es visto en la complejidad del testimonio de Cristo, es decir, en su vida, pasión, muerte y resurrección. Va colocado en el plano del seguimiento, pues sólo así se entiende que el don de la libertad sea vivido en la cotidianidad de la vida, sea profundizado en la responsabilidad histórica y pueda culminar, cuando es requerido, en el derramamiento de la propia sangre.

Se pueden testimoniar muchas realidades en el mundo: la justicia, los principios morales, la revolución, etc. Pero en el caso específico del testimonio cristiano, el mártir, por una parte intenta realizar plenamente su propio yo personal, pero como ese yo le ha sido donado, el martirio deviene un reditus, una profunda

73 Cfr. L. BOFF, «Martirio: tentativo di una riflessione sistematica», en Concilium 19 (1983), 38.

74 E. ESCHILLEBEECKX, Cristo, sacramento dell'incontro con Dio, Paoline, Roma 1981, 28.

75 Cfr. COLZANI, Antropologia teologica. L'uomo: paradosso e mistero, Dehoniane, Bologna 1988, 31; cfr. A.

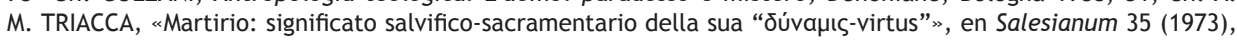
251-253. 
aspiración de trascendencia ${ }^{76}$, la culminación del estado de búsqueda y de precariedad que caracteriza normalmente la existencia histórica. Ahora bien, el hombre, en función de su ser libre, tiene abierta siempre la posibilidad de su no-libertad, es por ello que el testimonio en general y el martirio en particular, afronta al sujeto en la intimidad de su conciencia, lo obliga a tomar una decisión de frente a aquello que se revela como una realidad verdadera, el mártir debe ratificar su fe y su agradecimiento de frente al Dios de Jesús, que le hace existir como persona libre y racional.

De frente a la amenaza y al hecho mismo de la represión contra las personas el mártir encarna una «voluntad de significación» ${ }^{77}$, es decir, expresa la posibilidad real de que otro modo de convivir entre las personas es posible, es la rebelión total contra toda insignificancia existencial, es la esperanza cristiana en acto. Es esperanza porque, aunque el mártir encarne los valores del reino hasta las últimas consecuencias en el plano histórico, con ello no agota el misterio, sino que lo significa. En realidad, el martirio tiene sentido en este plano, en cuanto hace sentir más cercano al Dios que viene. Pero, aunque el mártir no agote el misterio, sin embargo con su testimonio entra en el misterio y, en los límites de su testimonio, comunica el misterio, es decir en él «la carne se hace palabra y la palabra se hace carne ${ }^{78}$. Su testimonio individual se redimensiona, alcanza valor universal y se consagra su originalidad, el mártir testimonia una realidad que lo sobrepasa. Como dice la 2Co 4,7: «llevamos este tesoro en recipientes de barro para que aparezca que una fuerza tan extraordinaria es de Dios y no de nosotros».

El mártir, alcanzando el máximo nivel de densidad significativa, se convierte, para la comunidad eclesial y para la comunidad humana en general, en palabra «nítida» al servicio de la revelación del Dios de Jesús. Su testimonio tiene una función recreativa, en cuanto que expresa el martirio de Jesús en el presente histórico; el mártir, entonces, interpela, sin hacer violencia a la libertad de sus interlocutores, proponiendo a otros esta entrega generosa que en él es ya una realidad; la aceptación de su invitación le da vida a la comunidad de los discípulos.

Es en este punto en que el perseguidor se equivoca y es cuando el martirio muestra toda su potencialidad dialéctica; el perseguidor piensa que matando al testigo anula el peligro de ser desenmascarado en su anti-testimonio. Todo

76 Cfr. E. BARBOTIN, «Le sens existentiel du temoignage et du martyre», en Revue des Sciences religieuses 35 (1961), 178. El derecho canónico, cuando juzga de la causa de los mártires, se atiene a la expresión pública, pero toda la riqueza de la realidad del martirio incluye también las motivaciones personales. En el mártir se da una tensión (kívnбıs), una intensidad personal que busca corresponder a la voluntad de Dios y una fuerza, una acción

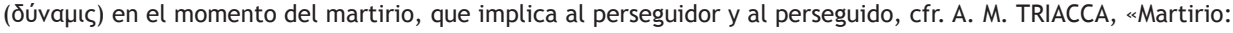
significato salvifico-sacramentario», 251-253.

77 E. BARBOTIN, «Le sens existentiel du temoignage et du martyre», 179.

78 Cfr. E. BARBOTIN, «Le sens existentiel du temoignage et du martyre», 180. 
lo contrario, es en ese momento que el mártir lo obliga a manifestar toda la potencialidad del mal que en él se esconde.

\subsection{Martirio, sacramento para todos los tiempos}

El martirio pertenece a pleno título a la vida de la iglesia ${ }^{79}$. El martirio es un acto de la iglesia ${ }^{80}$. Ignorar este principio es tener una falsa idea de lo que es la historicidad y sacramentalidad de la iglesia. Pues, siendo el martirio la máxima expresión del testimonio evangélico y expresando el testimonio evangélico -en el sentido de la misión cristiana - la naturaleza de la iglesia (AG 2), entonces, también el martirio es visto dentro de las coordenadas de la mediación, es decir, como «instrumento de unión íntima con Dios y de la unidad de todo el género humano» (LG 1). Ahora bien, los mártires reflejan el modo en que Jesús ejerció su sacramentalidad con respecto a Dios, es decir, con las persecuciones y la crucifixión. De modo que el martirio es un concentrado de aquello que se debe predicar de todos los miembros de la iglesia, es decir, que «es necesario que todos los miembros [del cuerpo] se asemejen a Él [...] Peregrinos todavía sobre la tierra, siguiendo sus huellas en el sufrimiento y en la persecución» (LG 7). Si la iglesia es «testigo entre los hombres de las cosas divinas»81, entonces aquellos miembros suyos, que anuncian el evangelio no sólo «por la predicación oral, sino sobre todo por la vida»82, hacen realidad aquello por lo cual únicamente tiene sentido la existencia de la iglesia: «hacer presente a Jesucristo a los hombres ${ }^{83}$. Si el mártir efectivamente logra eso, entonces está justificada su perenne actualidad.

\subsubsection{Bautismo y martirio}

Pero, concretemos mejor la sacramentalidad del martirio. Veamos, en primer lugar, la interacción bautismo-martirio. Según la tradición cristiana, se pasa a formar parte de la iglesia por medio del bautismo ${ }^{84}$, lo cual pone a todos los bautizados en perspectiva testimonial. La vocación al martirio consiste en llevar a «cumplimiento», a su «conclusión» y «perfección» la implícita vocación eclesial-bautismal. Dios Padre, de hecho, llama a «la plenitud de Cristo» (Ef 4,13 ) en la vocación bautismal, pero en modo particular en el martirio, donde se da una maduración precoz y una maduración intensiva de la gracia de Dios ${ }^{85}$.

En relación con el Hijo, está fuera de discusión la analogía del mártir con los padecimientos y la muerte de Jesús. Veamos un primer nivel de relación. Existe

79 Cfr. E. PETERSON, Tratados teológicos, Cristiandad, Madrid 1966, 76.

80 Cfr. M. PELLEGRINO, «Chiesa e martirio in Sant'Agostino», en Rivista di Storia e Letteratura Religiosa 1 (1965), 193.

81 H. DE LUBAC, Meditación sobre la iglesia, Encuentro, Madrid 1980, 174.

82 H. DE LUBAC, Meditación sobre la iglesia, 182.

$83 \mathrm{H}$. DE LUBAC, Meditación sobre la iglesia, 176.

84 Cfr. CCC, n. 1267.

85 Cfr. A. M. TRIACCA, «Martirio: significato salvifico-sacramentario», 266. 
una analogía entre Jesucristo y el mártir, esto es, lo que en el bautismo sucede por configuración sacramental, en el martirio sucede por configuración «semántico-mimética», semántica, porque significa la imagen de la vida de Cristo en su propia vida y mimético porque no sólo imita en el sentido moderno de la «mímesis», sino que reproduce y hace efectiva, en los límites del seguimiento, la obra salvífica que alcanza plenitud en Cristo. El mismo Jesús decía que tenía que ser bautizado aludiendo a la cruz (cfr. Lc 12,50). Con lo cual, su muerte es un bautismo de sangre y el bautismo es, en sentido estricto, una muerte en Cristo. De este modo, lo que en el bautismo es sólo una disposición constante, en el martirio es una realización puntual. El mártir es coheredero de las promesas del Padre por su íntima unión con el Hijo; así, entre el misterio pascual, el bautismo y el martirio se da un vínculo esencial ${ }^{86}$.

El segundo nivel en la analogía bautismo-martirio, es la coherencia ética en la vida del mártir. El punto de comunión con Cristo es el cumplimiento de la voluntad del Padre, una obediencia hasta la muerte. Esto normalmente se afirma desde el punto de vista de la fe. Pero el ser fieles a la voluntad del Padre se cumple además en otras virtudes. El defender la imagen de Dios en los derechos de las personas, por ejemplo, es una disposición legítima de testimonio delante a Dios, a la iglesia y al mundo. Al considerar la coherencia ética en el mártir se abre el tema del martirio a un universo más amplio de comprensión, esta ampliación no disminuye el sentido específico del martirio cristiano, más bien lo enriquece. De hecho, cuando nosotros encontramos personas en otras tradiciones religiosas, que se han entregado hasta la muerte por defender los derechos de la persona, esas acciones no pueden que tener hondas raíces evangélicas, pues Jesús fue asesinado, por mantener un estilo de vida coherente con sus principios y porque su predicación y sus acciones no correspondían con la versión oficial de la religión y del poder político de su tiempo ${ }^{87}$.

En el plano eclesial, la relación bautismo-martirio se hace en términos de credibilidad de la iglesia. Si el bautismo es el medio para incorporarse a la iglesia, el martirio es la expresión de la máxima vitalidad de la iglesia. Esto parece un juicio contradictorio, pero en realidad es dialéctico, en el sentido que el martirio es signo de la relación dialéctica que la iglesia debe mantener con el mundo, es su vanguardia y su termómetro ${ }^{88}$. Cuando la relación con el mundo es pacífica no hay mártires, pero, al mismo tiempo, cuando los mártires cesan esto significa que la iglesia ha perdido su credibilidad, es decir, se ha acomodado a las estructuras del mundo, ha perdido vitalidad. En esta perspectiva el mártir no debe ser reducido a ser el «defensor de un cuerpo doctrinal», sino que es un

86 Cfr. A. M. TRIACCA, «Martirio: significato salvifico-sacramentario», 268.

87 Cfr. J. M. TOJEIRA, El martirio ayer y hoy. Testimonio radical de fe y justicia, UCA Editores, San Salvador 2001, 140-141.

88 J. ZVĚŘíNA, «Meditazione sulla persecuzione», en Communio 92 (1987), 3. 
"creador de la iglesia»89. El bautizado, en modo particular el mártir, provocan una crisis y cuando se ataca a un bautizado es a Cristo que se persigue: «Así también cada uno de nosotros lleva una responsabilidad de la cual él no es dueño, uno ya es un responsable de Cristo y tiene que dar fe»90. La iglesia, si es verdadera, está llamada a «inquietar las conciencias, provocar crisis en la hora que vive», pues «una palabra de Dios que no toca el pecado concreto de la sociedad en que está anunciándose, ¿qué evangelio es ése?»»1.

\subsubsection{Eucaristía y martirio}

Como sostiene Ratzinger, la teología de la cruz es el presupuesto y el fundamento de la teología eucarística. El papa alemán sostiene que «la teología de la cruz es teología eucarística y viceversa ${ }^{92}$. De modo que para una justa comprensión de la eucaristía se requieren tres niveles: la teología de la cruz, la teología del sacramento eucarístico y la teología del martirio ${ }^{93}$. No interesa en este momento desglosar la correlación entre estos tres aspectos, interesa sólo la concepción que el Ratzinger teólogo tiene del martirio en perspectiva litúrgica.

La muerte testimonial del apóstol, dice Ratzinger, tiene carácter litúrgico, es un dejar derramar la propia vida por los hombres ${ }^{94}$. Así como en el caso de Policarpo, el martirio es descrito como liturgia, es más, como devenir eucaristía. El mártir entra en la plena comunión con la Pascua de Jesucristo y así deviene con él eucaristía 95 . Entrando en el misterio, el mártir, con su muerte, vive y da vida. El martirio es, así, fuente de la fe. En este modo, también nuestra vida se transforma en don para los hombres, culto de Dios y eucaristía vivida ${ }^{96}$.

El primer impulso a la hora de tratar la relación martirio-eucaristía es ir, en modo inmediato, al martirio de Cristo viéndolo desde el punto de vista cultual, como víctima propiciatoria, como sacrificio. Esto es verdad, pero va colocado en el contexto de las razones históricas de la muerte de Jesús, en el por qué de su muerte y el por qué lo matan. Los padres de la iglesia sostienen con fuerza que la iglesia nace del martirio de Cristo, es decir, después de su muerte y de su resurrección, y esa afirmación incluye a la liturgia, que forma parte de la vida de la iglesia, de modo que a la lex orandi y la lex credendi hay que conjugarlas siempre con la lex vivendi. Todo lo que se diga de la muerte y de la resurrección de Cristo tiene sentido sólo en el conjunto de su existencia y no simplemente con el momento puntual de su sacrificio en cruz.

89 Cfr. J. M. TOJEIRA, El martirio ayer y hoy, 139.

90 O. A. ROMERO, SP, vol. 4, 53.

91 O. A. ROMERO, SP, vol. 4, 140.

92 J. RATZINGER, La comunione nella chiesa, San Paolo, Cinisello Balsamo (MI) 2004, 101.

93 Cfr. J. RATZINGER, La comunione nella chiesa, 102.

94 Cfr. J. RATZINGER, La comunione nella chiesa, 117.

95 Cfr. Ibídem.

$96 \mathrm{Cfr}$, J. RATZINGER, La comunione nella chiesa, 119. 
La clave de lectura del sentido litúrgico de la muerte de Jesús, sin tener que saltarse el conjunto de su vida, la da la Epístola a los Hebreos, en ella se afirma con fuerza la lex vivendi en la humanidad de Jesús, el cual «habiendo ofrecido en los días de su vida mortal ruegos y súplicas con poderoso clamor y lágrimas al que podía salvarle de la muerte, y aun siendo Hijo, con lo que padeció experimentó la obediencia» (5,7-8); esa fidelidad a Dios a lo largo de su existencia hasta la muerte (cfr. $\mathrm{Hb} 2,9$ ) es lo que después la lex orandi proclama: «y llegado a la perfección, se convirtió en causa de salvación eterna para todos los que le obedecen, proclamado por Dios Sumo Sacerdote a semejanza de Melquisedec $\gg(5,9-10)$.

La eucaristía no se reduce, entonces, al momento ritual de su celebración, sino que va vista en todo su dinamismo, entre el ser fuente y culmen de toda la vida de la iglesia ${ }^{97}$, la existencia misma puede ser considerada como una «misa prolongada» ${ }^{98}$. En ella encontramos todo el bien espiritual de la iglesia, Cristo y su Pascua. Ahora bien, que la eucaristía sea sacrificio significa que en ella se re-produce (se hace presente) el sacrificio de la cruz, en cuanto memorial y porque en ella se hacen efectivos sus frutos. Esto significa que si el mártir porta en sí el morir de Jesús -a fin de que la vida de Jesús se manifieste en su cuerpo (cfr. 2Co 4,10)-, ello significa que porta también, en el presente histórico, las señales de Cristo (cfr. Ga 6,17) y completa en sí lo que falta a las tribulaciones de Cristo (cfr. Col 1,24), entonces también el mártir, en esa medida, re-produce el sacrifico de Cristo y, en cuanto tal, entra en el misterio eucarístico, y no lo hace sólo en el orden del signo, de modo sacramental, sino realizándolo (in re) en su propia vida, se trata de la superación, por vía de plenitud, de la mediación sacramental ${ }^{99}$.

En el mártir es el amor el que hace de quicio entre la comunidad y el Dios de Jesús al cual testimonia. Resaltando el sentido sacrificial de la muerte de Cristo se realiza un movimiento "centrípeto» hacia aquello que constituye el corazón del rito eucarístico, pero hemos dicho que ese misterio es un dinamismo amplio que comprende toda la vida de la iglesia, con lo cual, hablando del martirio desde el misterio de la caridad, lo que hacemos es situarnos en un movimiento "centrífugo", de servicio al reino, que sólo puede ser comprensible desde el sentido de servicio que tiene la Pascua de Cristo. El evangelio de Juan propone una escena que ilustra y fundamenta muy bien esto que estamos diciendo. En el contexto de la última cena, en pleno contexto pascual, en el momento que Juan llama «la hora de Jesús», se dice que Jesús: "se levanta de la mesa, se quita sus vestidos y, tomando una toalla, se la ciñó. Luego echa agua en un lebrillo y se puso a lavar los pies de los discípulos» $(13,4-5)$. Entre el primer movimiento de Jesús hacia sus discípulos para lavar sus pies y la conclusión, 
hay una escena intermedia. Pedro se niega a que Jesús le lave los pies, y Jesús insiste que para tener parte con él es necesario entrar en la dimensión del servicio. Sólo entonces Pedro acepta (cfr. 13,6-11). Se da en esa escena una especie -si se nos permite la expresión- de conversio brevis de Pedro. Pero, vayamos la narración. Una vez lavados los pies,

\begin{abstract}
"Tomó sus vestidos, volvió a la mesa, y les dijo: “¿Comprendéis lo que he hecho con vosotros?" Vosotros me llamáis "el Maestro" y "el Señor", y decís bien, porque lo soy. Pues si yo, el Señor y el Maestro, os he lavado los pies, vosotros también debéis lavaros los pies unos a otros. Porque os he dado ejemplo, para que también vosotros hagáis como yo he hecho con vosotros" $(13,12-15)$.
\end{abstract}

La escena se da en un contexto pascual, se dice primero que Jesús «les amó hasta el extremo» $(13,1)$, que fue «durante la cena» $(13,2)$ y que se trataba de la muerte y resurrección de Jesús, pues de Dios había salido y «a Dios volvía» $(13,3)$. Esta breve afirmación muestra la dinámica en la cual Jesús quiere hacer entrar a sus discípulos: salir de Dios $\longrightarrow$ venir al mundo $(3,19)$ $\longrightarrow$ volver a Dios, se concreta en la comunidad de los discípulos: levantarse (dejar) la mesa, quitarse los vestidos $\rightarrow$ lavar los pies $\rightarrow$ vestirse de nuevo, retornar a la mesa. Se da un primer movimiento de Jesús, que nosotros llamamos «centrífugo», porque deja la mesa, se quita sus vestidos; el centro de la escena es el lavatorio de los pies, y luego se da el movimiento de retorno, el «centrípeto», tomó sus vestidos y volvió a la mesa. Según nuestro punto de vista es éste el dinamismo que debe caracterizar una iglesia martirial, una iglesia con una circularidad dinámica entre la celebración del sacrificio de Cristo, en el orden ritual y un servicio al mundo en el horizonte del reino.

En cuanto respecta la escena de Pedro, él normalmente es visto como expresión de la institucionalidad de la iglesia. Llama la atención que el evangelista lo presente confuso de frente al gesto realizado por Jesús. La iglesia debe estar en estado constante de conversión; no debe confiar sólo en sus estructuras, debe «quitarse los vestidos», "desnudarse» de todo aquello que le impide o entorpece el ejercicio de su sacramentalidad. Debe renunciar a la pompa triunfal y recuperar con humildad su precariedad de sierva, debe «dejar la mesa», en particular cuando se la confunde con un trono, ceñirse una toalla y ponerse a curar las heridas que el pecado genera en el mundo. La iglesia de los mártires ha sido despojada de todos sus poderes y afronta con responsabilidad sacramental el silencio de Dios en la hora de su pasión. Sólo así puede ser una iglesia creíble. Va pues, entendida correctamente la participación de la iglesia en la realeza de Cristo a tenor del n. 786 del Catecismo de la Iglesia Católica: 
Para el cristiano, "servir es reinar" (LG 36), particularmente "en los pobres y en los que sufren" donde descubre "la imagen de su Fundador pobre y sufriente" (LG 8). El pueblo de Dios realiza su "dignidad regia" viviendo conforme a esta vocación de servir con Cristo.

La sacramentalidad responsable, vista desde la óptica del martirio, es, entonces, el intento por demostrar que la sacramentalidad de la iglesia no debe significar sólo la afirmación eminente de un aspecto esencial en la doctrina de la iglesia. Debe comportar además una puesta en práctica de esa afirmación. La primera cuestión ha sido afirmar que la sacramentalidad tiene su fundamento en Jesucristo, sacramento originario y que todo lo que se diga del martirio y de la sacramentalidad de la iglesia, está referido a ese fundamento y, en definitiva, al misterio trinitario.

La segunda cuestión se refiere a la indispensable respuesta del hombre, desde su libertad, al don de Dios que en ella se manifiesta. El mártir, con su testimonio radical, lo que hace es «restituir» algo que ha recibido como don de Dios: su libertad.

En tercer lugar, con su disposición radical, el mártir, se convierte a semejanza de Jesucristo, en un sacramento de la revelación de Dios en la historia; el mártir entrando en el misterio es causa de fe, no agota el misterio, pero acerca ese misterio a los hombres.

En fin, hemos presentado la relación del martirio con el bautismo y la eucaristía, como expresión concreta de su presencia constante al interno dinamismo sacramental de la iglesia. Sobre todo de la relación eucaristía-martirio hemos recabado el elemento que indica lo que puede significar el hablar de una iglesia martirial. El resultado es una iglesia que pone su institucionalidad al servicio del encuentro de Dios con los hombres, que reconoce que para lograr esto tiene que despojarse de todo aquello que hace de muro de separación entre ella y el mundo; que el derribar ese muro no significa necesariamente que ella pierda su identidad, sino reconociendo su precariedad y el sentido dialéctico de su estar en el mundo, se pueda hacer cercana a los sufrimientos que afligen al mundo y se pueda enriquecer con los aportes que puedan venir de otras tradiciones religiosas.

\section{Conclusión}

Una lectura eclesial del martirio comporta una serie de elementos que no tienen que ser inventados de la nada, sino que se fundan en la tradición cristiana, en la forma típica del martirio. Pero esa forma típica se debe enriquecer, además, con las nuevas expresiones del martirio, así como han sido vividas a lo largo del siglo XX. 
Dos aspectos de particular importancia son resaltados: en primer lugar, el retorno al martirio de los obispos y de los laicos. Desde hace mucho tiempo era prácticamente imposible encontrar un obispo entre los modelos de santidad de nuestro tiempo, por lo general eran los fundadores de órdenes religiosas los que acaparaban el espacio de la canonización de santos. En segundo lugar, se entra en una dimensión participativa de la vida de la iglesia; se da una interacción entre la praxis eclesial y la reflexión teológica, el eclesiólogo no habla de lo que él cree que sea o pueda ser la iglesia, sino de aquello que la iglesia es en su itinerario histórico.

Esta visión del martirio resulta incómoda, porque precisamente no se acomoda a la visión clásica, aquí se ha pasado del odium fidei, al odium caritatis, pero ello no significa que sea una visión falsa; con ella simplemente se está reclamando a las instancias que desde Benedicto XIV, entiéndase del derecho canónico, han determinado el sentido del martirio cristiano ${ }^{100}$, a abrirse al debate teológico, para poder generar un espacio real al tema del martirio en el ejercicio de la teología, que se pueda hablar de verdadero martirio y no de un martirio de segundo grado en otras comunidades cristianas no católicas y que se plantee el debate en vistas a un contexto multicultural y multirreligioso, donde el sentido de la transmisión de la fe tendría que ser retomado ${ }^{101}$.

\section{Bibliografía}

I. ELLACURÍA, Filosofía de la realidad histórica, UCA Editores, San Salvador 1990. Editores, San Salvador 2000.

I. ELLACURÍA, Teología política, UCA Editores, San Salvador 1972.

D. BONHOEFFER, Etica, Trotta, Madrid 2000.

D. BONHOEFFER, Resistencia y sumisión. Cartas y apuntes desde el cautiverio, Sígueme, Salamanca 2001.

C. DOTOLO, Un cristianesimo possibile, Queriniana, Brescia 2007.

I. ELLACURÍA, Conversión de la iglesia al reino de Dios, Sal Terrae, Santander 1984.

100 Cfr. B. GHERARDINI, «ll martirio nella moderna prospettiva teologica», en Divinitas 36 (1982), 19, 28. Incluso la línea editorial de la Civiltà Cattolica, que no es precisamente expresión de progresismo teológico, acepta que el concepto canónico martirio debe ser alargado, cfr. «ll senso del martirio cristiano», 112-113; 156 (2005, I), 321-322.

101 Para el debate sobre el martirio en el contexto del pluralismo religioso véase F. WILFRED, «ll martirio nelle tradizioni religiose», en Concilium 39 (2003), 100-111. 
I. ELLACURÍA, «Utopía y profetismo desde América Latina», ID., ET, vol. 2, UCA Editores, San Salvador 2000.

E. JÜNGEL, El ser sacramental. En perspectiva evangélica, Sígueme, Salamanca 2007.

K. RAHNER, Sulla teologia della morte. Con una digressione sul martirio, Morcelliana, Brescia 1972.

CH. DUQUOC, Iglesias provisionales. Ensayo de eclesiología ecuménica, Cristiandad, Madrid 1986. 